\title{
Thyroid status and functional and cognitive status at baseline and survival after 3 years of follow-up: the OCTABAIX study
}

\author{
Francesc Formiga ${ }^{1}$, Assumpta Ferrer ${ }^{2}$, Gloria Padros ${ }^{3}$, Anna Contra', \\ Xavier Corbella ${ }^{1,4}$, Ramon Pujol ${ }^{1}$ and on behalf of the Octabaix Study Group ${ }^{\dagger}$ \\ ${ }^{1}$ Geriatric Unit, Internal Medicine Service, IDIBELL, Hospital Universitari de Bellvitge, L'Hospitalet de Llobregat, \\ 08907 Llobregat, Barcelona, Spain, 2Primary Health Care Centre 'El Plà' CAP-I, Sant Feliu de Llobregat, Barcelona, \\ Spain and ${ }^{3}$ Laboratori Clínic Metropolitana Sud, Atenció Primària, L'Hospitalet de Llobregat, Barcelona, Spain and \\ ${ }^{4}$ Global Institute of Public Health and Health Policy, Faculty of Medicine and Health Sciences, Universitat \\ Internacional de Catalunya, Barcelona, Spain \\ ${ }^{\dagger}$ (The members of the Octabaix Study Group is presented in the Acknowledgements section).
}

Correspondence should be addressed to F Formiga Email fformiga@ bellvitgehospital.cat

\begin{abstract}
Objective: Subclinical thyroid disorders are common in older individuals. Health risks associated with subclinical hypothyroidism in older adults are unclear. The aim of the study is to evaluate whether thyroid status in elderly subjects correlates with physical and cognitive function at baseline and with 3-year mortality.

Design: A population-based, prospective cohort of the OCTABAIX study (307 inhabitants aged 85 years at baseline).

Methods: Chronic drug prescription, functional status (Barthel and Lawton indices) and cognitive status according to the Spanish version of the Mini-Mental State Examination were recorded. Quality of life was assessed using the visual analogue scale of the quality of life test. Concentrations of TSH and thyroxine were measured. Participants were classified in accordance with clinical categories of thyroid function.

Results: Twenty (6.5\%) individuals had subclinical hypothyroidism and five (1.6\%) had subclinical hyperthyroidism. Compared with euthyroid subjects ( $n=280 ; 91.8 \%$ ), subclinical hypo- and hyperthyroidism subjects were not significantly associated with poor physical or cognitive function at baseline. Fifty-one (15.1\%) subjects died during the 36 months of follow-up. TSH values and subclinical hypo- and hyperthyroidism were not associated with an increased overall mortality risk (hazard ratio (HR) 1.086, 95\% Cl 0.987-1.196 and HR 0.905, 95\% Cl 0.902-1.053 respectively).

Conclusions: This study does not support the association of TSH or thyroid disorders with physical or cognitive function at baseline or with 3-year mortality in the oldest old subjects.
\end{abstract}

\section{Introduction}

Thyroid function seems to have a role in the modulation of oxidative stress, one of the most popular theories to explain the ageing phenomenon (1). Abnormalities in thyroid function are frequently observed in ageing populations with the most prevalent type being subclinical hypothyroidism $(2,3,4,5)$. Although overt thyroid disorders negatively influence physical and cognitive function, the association of subclinical thyroid disorders with these outcome measures is less clear and studies demonstrate contradictory results $(6,7,8,9)$.

The results of studies on the association between decreased serum thyrotrophin (TSH) levels and all-cause mortality are also conflicting $(3,9,10,11,12,13,14$, $15,16)$. The inconsistent results from prospective studies
(ㄷ) 2014 European Society of Endocrinology Printed in Great Britain
Published by Bioscientifica Ltd. 
may be due to differences in age, gender, different duration of follow-up and other characteristics of the participants. Subclinical hypothyroidism has been associated with negative clinical outcomes in older adults, such as abnormalities in lipid profile and poor cardiovascular function. Some studies found an association between subclinical hypothyroidism and all-cause and cardiovascular mortality, but other studies did not $(9,10,11,12,13$, $14,15,16)$. Moreover, some reports indicate that in the oldest of elderly subjects, high levels of TSH are associated with a prolonged lifespan $(14,15,16)$.

The aims of our study were twofold. The first objective was to evaluate the correlation between TSH levels/thyroid status and functional and cognitive status at baseline. Our second objective was to determine the possible association between TSH values and mortality in an elderly cohort of inhabitants aged 85 years at baseline after 3 years of follow-up.

\section{Subjects and methods}

The OCTABAIX study is a prospective cohort study incorporating a double-blind, parallel-group, randomized clinical trial on falls and nutritional risk. A total of 328 community-dwelling persons born in 1924 (85 years old at the time of inclusion) who were registered at one of seven primary care teams in the geographical area of Baix Llobregat, Barcelona, Spain, were included; this sample is described in more detail elsewhere $(17,18)$. In brief, every old inhabitant was interviewed at their home or their health centre by a research team with training in geriatrics. The Institutional Ethics Committee of the local health system approved the design of the study and all patients, or the caregivers of cognitively impaired subjects, gave their written informed consent before enrolment. No criteria related to baseline health or cognitive status were used to exclude patients. Sociodemographic data (gender, marital status, place of residence, educational level and living alone) and a comprehensive geriatric evaluation (functional, cognitive and nutritional status, social risk, gait and risk of falls) based on tools currently used in geriatric practice were included in this evaluation.

Functional status was measured using the Barthel index (BI) (19) for basic activities of daily living (ADL) and the Lawton index (LI) (20) for instrumental ADL. The LI is an easy-to-administer assessment instrument that provides self-reported information about functional skills necessary to live in the community. The BI measures include questions about seven areas: feeding, bathing, personal hygiene, dressing, bowel/bladder control, getting on/off the toilet and locomotion. A maximum score of 100 indicates that the subject is independent in physical function and the lowest score of 0 indicates a totally dependent state. LI scores range from 0 (low function, dependent) to 8 (high function, independent). Historically, women were scored on all eight areas of function; men were not scored in the domains of food preparation, housekeeping or laundering. However, we applied the current recommendations to assess all domains for both genders (18). A limitation of the instrument includes the self-report or surrogate report method of administration rather than a demonstration of the functional task. Cognitive function was measured using the Spanish version of the Mini-Mental State Examination (MEC) (21), which has a total score of 35 and takes particular account of the very low educational level of the elderly Spanish population. As recommended, we considered scores below or equal to 23 to indicate the presence of cognitive impairment. We defined non-disabled subjects as those with a better health status (successful age), who, in addition to being non-institutionalized, had scores of 91 or higher on the BI and 24 or higher on the MEC, criteria that we had already used to assess the oldest old population in our area (18).

Nutritional status was assessed using the Mini Nutritional Assessment (MNA) (22). The MNA score is based on 18 items covering four component sub-scores: MNA-1 (four items), anthropometric measurement ( $0-8$ points); MNA-2 (six items), overall evaluation (0-9 points); MNA-3 (six items), assessment of dietary habits ( $0-9$ points); and MNA-4 (two items), subjective assessment of self-perceived quality of health and nutrition ( $0-4$ points). The score obtained (maximum 30 points) classifies the subjects assessed into three categories: $24-30$, well nourished; $17-23.5$, at risk of malnutrition; and $<17$, malnourished. Gait was evaluated using the Gait Rating Scale from the Tinetti PerformanceOriented Mobility Assessment (23). The gait component of this scale evaluates seven items: initiation of gait, step height and length, step symmetry and continuity, path deviation, trunk stability, walking stance and turning while walking. The scale provides a final score that ranges from 0 to 12 , with a higher score indicating better gait performance. Quality of life was assessed using the visual analogue scale of the Quality of Life Test (EQ-VAS) of perceived health (24). The EQ-VAS records the respondent's self-rated health on a $20 \mathrm{~cm}$ vertical, visual analogue scale with endpoints labelled 'the best health you can imagine' (100) and 'the worst health you can imagine' (0).

The Charlson score (CS) was used to measure overall comorbidity (25). It ranges from 0 to a theoretical 
maximum of 33, depending on the presence of certain diseases with assigned values. The age-adjusted CS was not used as all participants were 85-year olds. Cardiovascular risk factors such as treatment for high blood pressure above 140/90 (clinical measurement of blood pressures calculated using the average of two morning measurements in the upright position), diabetes mellitus and dyslipidaemia were also recorded. Disease prevalence for stroke and dementia was determined on the basis of data review from general practice records. The number of drugs used by prescription on a chronic basis was also recorded. In most cases, the physician who obtained the information was at the same time the one who usually cared for the patient - comorbidity data were therefore derived not only from self-report but also from chart reviews, test results and prescription drug indications. Patients and/or caregivers were asked about any previous falls in the last year.

\section{Laboratory measures}

Blood samples were collected in the morning after a 12-h fast. Aliquots of serum were obtained and processed immediately. Plasma concentrations of TSH and free thyroxine $\left(\mathrm{FT}_{4}\right)$ were measured using an electrochemiluminescence immunoassay based on the sandwich principle with MABs (Roche Diagnostics). The reference range was $0.25-5 \mathrm{mU} / 1$ for TSH and $10-26 \mathrm{pmol} / \mathrm{l}$ for $\mathrm{FT}_{4}$. Assay sensitivities were $0.005 \mathrm{mU} / 1$ for TSH and $0.03 \mathrm{pmol} / 1$ for $\mathrm{FT}_{4}$. Inter-assay coefficients of variation were $1.96-3.56 \%$ over the range $0.005-100 \mathrm{mU} / \mathrm{l}$ for TSH and $1.91-3.68 \%$ over the range $0.3-100 \mathrm{pmol} / \mathrm{l}$ for $\mathrm{FT}_{4}$.

\section{Definition of thyroid function}

Complete data on thyroid hormones were available in 318 (96.9\%) participants. We excluded the 11 participants who were undergoing chronic treatment with drugs known to affect thyroid function, including thyroid hormone preparations, methimazole, propylthiouracil and lithium. Thyroid function was measured at baseline. Participants were classified according to TSH and $\mathrm{FT}_{4}$ hormone concentrations into five categories: overt hypothyroidism (TSH $>5 \mathrm{mU} / \mathrm{l}, \mathrm{FT}_{4}<10 \mathrm{pmol} / \mathrm{l}$ ), subclinical hypothyroidism (TSH $>5 \mathrm{mU} / \mathrm{l}, \mathrm{FT}_{4} 10-26 \mathrm{pmol} / \mathrm{l}$ ), euthyroidism (TSH $\left.0.25-5 \mathrm{mU} / \mathrm{l}, \quad \mathrm{FT}_{4} \quad 10-26 \mathrm{pmol} / \mathrm{l}\right)$, subclinical hyperthyroidism (TSH $<0.25 \mathrm{mU} / \mathrm{l}, \mathrm{FT}_{4} \quad 10-26 \mathrm{pmol} / \mathrm{l}$ ) and overt hyperthyroidism (TSH $<0.25 \mathrm{mU} / \mathrm{l}$, with $\mathrm{FT}_{4}$ $>26 \mathrm{pmol} / \mathrm{l}$ ).

\section{Outcome events: mortality}

Mortality, measured as time-to-event data, was the main outcome of this study. The vital status of the participants was thus intermittently evaluated during the 3 years of follow-up. Participants were categorized as alive after 36 months of follow-up or censored when they died. Mortality status and causes of death were determined by trained physician adjudicators on the basis of medical records from hospitalizations and emergency room visits, death certificates and autopsy and coroner's reports, when available. We compared the patients who survived with those who died.

\section{Statistical analysis}

Normally distributed continuous variables are reported as mean \pm s.D. Categorical variables are reported as proportions. Normal or non-normal distributions of continuous variables were assessed using the KolmogorovSmirnov test. The Student's $t$-test was used to compare continuous variables, following the Levene test for equality of variances, while either the $\chi^{2}$ statistic or Fisher's exact test was used to compare categorical or dichotomous variables. Spearman and Pearson correlations were used. Cox models were adjusted between the main outcome variable and predictors. The semiparametric Cox proportional hazards model analyzed the relationship between the time-to-event response variable and adjusted baseline covariates. Proportional hazards and linearity (on continuous variables) assumptions were evaluated for the Cox models to determine the variables associated with 3-year mortality. The variables entered into the model using a backward stepwise approach were those for which a significant association was previously reported in the total cohort, that is the LI and chronic drugs prescription, as well as gender, BI and MEC. We ran the model again after adding thyroid status as categorical scores and TSH mean values as continuous variables. An adjusted hazard ratio (HR) with a 95\% CI was used. The results were considered significant when $P<0.05$. All analyses were performed using SPSS 15.0 Statistical Software (SPSS, Inc.).

\section{Results}

The sample included the 307 subjects from whom baseline TSH and $\mathrm{FT}_{4}$ values were recorded (184 women (54.6\%) and 123 men). Geriatric assessment tools at baseline showed the following mean values: BI $87.4 \pm 19$ for basic 
ADL, LI $5.3 \pm 2.5$ for instrumental ADL, MEC 26.7 \pm 6.7 and MNA $24.4 \pm 3.7$ for malnutrition risk and Tinetti Gait Scale $6.6 \pm 2.8$ for risk of falls. The mean quality-of-life score assessed using the EQ-VAS was $62.5 \pm 21$. The mean Charlson index was $1.4 \pm 1.5$.

The mean TSH levels were $2.7 \pm 2.6 \mathrm{mU} / 1$. The majority of participants (282 (91.8\%) ) had normal thyroid function, 20 (6.5\%) had subclinical hypothyroidism and five $(1.6 \%)$ had subclinical hyperthyroidism. TSH was not correlated with basal BI $(r=0.08 ; P=0.14)$, LI $(r=0.06$; $P=0.29)$ or MEC $(r=-0.03 ; P=0.52)$. Likewise, TSH was not correlated with MNA $(r=0.05 ; P=0.32)$, Tinetti Gait Scale $(r=0.05 ; P=0.31)$ or EQ-VAS $(r=0.07 ; P=0.18)$. A total of 127 falls was recorded, with a mean of $0.4 \pm 0.9$ falls per subject. Table 1 shows baseline characteristics of participants according to thyroid function.

\section{Evaluation after 3-year follow-up}

Fifty-one subjects died during the 36-month follow-up period (15.1\%). There were no differences in TSH values between subjects who survived or died $(2.9 \pm 2.3$ vs 2.4 $\pm 2.1 \mathrm{mU} / \mathrm{l} ; P=0.12$ ), nor was there any association with mortality at 1 year $(2.5 \pm 1.2$ vs $2.5 \pm 2.1 \mathrm{mU} / \mathrm{l} ; P=0.94)$ or 2 years of follow-up $(2.7 \pm 2.4$ vs $2.5 \pm 2.1 \mathrm{mU} / 1 ; P=0.58)$. When considering only the 282 euthyroid patients, there were no differences in TSH values between individuals who died and those who survived after 3 years of follow-up $(2.3 \pm 1.1$ vs $2.1 \pm 1.1 \mathrm{mU} / 1 ; P=0.28)$.

Of the 256 surviving patients, we performed a geriatric assessment on 205 patients, revealing a mean BI of 81.4 \pm 25 , LI of $4.8 \pm 2.7$ and MEC of $25.8 \pm 10$. TSH was not correlated with 3 -year BI $(r=0.11 ; P=0.11)$, LI $(r=0.09$; $P=0.18)$ or $\operatorname{MEC}(r=-0.08 ; P=0.22)$.

\section{Predictors of mortality}

Cox regression analysis identified two significant clinical variables (LI values and number of chronic drugs used) as independent predictors of 3-year risk of mortality for this cohort of octogenarians (Table 2). LI and chronic drug prescription were not affected by the introduction of

Table 1 Baseline characteristics of participants aged 85 years according to thyroid function. Proportions and mean (s.D.) are shown.

\begin{tabular}{|c|c|c|c|c|}
\hline & Normal $(n=282)$ & $\begin{array}{c}\text { Subclinical } \\
\text { hypothyroidism }(n=20)\end{array}$ & $\begin{array}{c}\text { Subclinical } \\
\text { hyperthyroidism }(n=5)\end{array}$ & $\boldsymbol{P}$ \\
\hline Gender & & & & 0.89 \\
\hline Female & $170(60.3 \%)$ & $11(55 \%)$ & $3(60 \%)$ & \\
\hline Male & $112(39.7 \%)$ & $9(45 \%)$ & $2(40 \%)$ & \\
\hline Marital status & & & & 0.06 \\
\hline Widowed & $118(41.8 \%)$ & $12(60 \%)$ & $1(20 \%)$ & \\
\hline Single & $16(5.7 \%)$ & $2(10 \%)$ & $2(40 \%)$ & \\
\hline Married & $148(52.5 \%)$ & $6(30 \%)$ & $2(40 \%)$ & \\
\hline Education & & & & 0.53 \\
\hline No education & $101(35.8 \%)$ & $4(20 \%)$ & $1(20 \%)$ & \\
\hline Primary school & $130(46.1 \%)$ & $9(45 \%)$ & $3(60 \%)$ & \\
\hline High school & $39(13.8 \%)$ & $5(25 \%)$ & $1(20 \%)$ & \\
\hline University degree & $12(4.3 \%)$ & $2(10 \%)$ & $0(0 \%)$ & \\
\hline Successful ageing & $140(49.6 \%)$ & $9(45 \%)$ & $2(40 \%)$ & 0.84 \\
\hline Barthel index & $86.9 \pm 20$ & $93.5 \pm 9$ & $90.0 \pm 10$ & 0.33 \\
\hline MEC & $26.8 \pm 6.6$ & $24.7 \pm 8$ & $28.6 \pm 7.8$ & 0.34 \\
\hline Lawton IADL index & $5.3 \pm 2.6$ & $5.4 \pm 2.2$ & $5.3 \pm 2.5$ & 0.96 \\
\hline EQ-VAS & $62.4 \pm 21$ & $63.5 \pm 20$ & $61 \pm 14$ & 0.96 \\
\hline Charlson index & $1.4 \pm 1.6$ & $1.9 \pm 1.6$ & $1.0 \pm 1.1$ & 0.38 \\
\hline MNA & $24.4 \pm 3.8$ & $24.7 \pm 2.9$ & $25.7 \pm 2.5$ & 0.69 \\
\hline Tinetti Gait Scale & $6.6 \pm 2.8$ & $7.3 \pm 2.8$ & $6.4 \pm 3.2$ & 0.51 \\
\hline Falls last year & $0.4 \pm 0.9$ & $0.4 \pm 0.6$ & $0 \pm 0$ & 0.61 \\
\hline Hypertension & $212(75.2 \%)$ & $15(75 \%)$ & $5(100 \%)$ & 0.24 \\
\hline Diabetes mellitus & $46(16.3 \%)$ & $7(35 \%)$ & $2(40 \%)$ & 0.07 \\
\hline Dyslipidaemia & $146(51.8 \%)$ & $10(50 \%)$ & $2(40 \%)$ & 0.86 \\
\hline Heart failure & $36(12.8 \%)$ & $4(20 \%)$ & $0(0 \%)$ & 0.33 \\
\hline Medical history of stroke & $47(16.7 \%)$ & $1(5 \%)$ & $0(0 \%)$ & 0.23 \\
\hline Dementia & $28(9.9 \%)$ & $0(0 \%)$ & $0(0 \%)$ & 0.08 \\
\hline Number of drugs taken & $6.1 \pm 3.3$ & $5.8 \pm 3.3$ & $4.6 \pm 2.1$ & 0.57 \\
\hline
\end{tabular}

MEC, Spanish version of the Mini-Mental State Examination; IADL, instrumental activities of daily life; EQ-VAS, quality of life with the visual analogue scale; MNA, Mini Nutritional Assessment questionnaire.

www.eje-online.org 
Table 2 Adjusted Cox regression analysis model of baseline variables for the death of oldest old subjects after a 3-year follow-up.

\begin{tabular}{|c|c|c|}
\hline & Hazard ratio & $95 \% \mathrm{Cl}$ \\
\hline Lawton IADL index & 0.83 & $0.754-0.930$ \\
\hline $\begin{array}{l}\text { Number of chronic } \\
\text { drug prescriptions }\end{array}$ & 1.124 & $1.037-1.219$ \\
\hline
\end{tabular}

thyroid status as a categorical variable in the evaluation (HR 0.905, 95\% CI 0.902-1.053), nor by the introduction of the TSH values as a continuous variable (HR 1.086, 95\% CI 0.987-1.196).

\section{Discussion}

Most of the 85-year-old inhabitants evaluated had normal thyroid function, with a slightly higher percentage than those in the Leiden 85-Plus Study (91.8 vs 85\%) (14), along with slightly higher percentages of subclinical hypothyroidism (6.5 vs 5\%) and slightly lower percentages of subclinical hyperthyroidism (1.6 vs 3\%) (14).

Our results provide no evidence of any effect of thyroid status on functional and cognitive function. Similarly, in the Leiden 85-Plus Study with the same aged subjects at baseline, there was no association between levels of TSH and disability in ADLs, disability in instrumental ADLs or cognitive function (14). Simonsick et al. (8) evaluated 2290 community-dwelling residents participating in the Health, Aging and Body Composition Study and used functional mobility (the capacity to walk $20 \mathrm{~m}$ unaided) as a marker of health status in a younger population (mean age of 74.6 years). In this study, the authors found no negative influence of subclinical hypothyroidism and those with mildly elevated TSH level even showed a slight functional advantage. Our participants also differed in accordance with thyroid values in terms of scores of risk scales of falls such as the Tinetti Gait Scale. In the OCTABAIX study, there were no differences in the number of falls according to thyroid status. By contrast, a study evaluating older subjects (mean age 90.3 years) showed that participants who did fall had significantly higher TSH levels (26). A topic that is interrelated with function and cognition is quality of life. As reported previously (27), we found no differences in quality of life according to thyroid status in these elderly subjects.

In this cohort of community-dwelling elderly people, we found no evidence of an association between mean TSH values and all-cause 3-year mortality. There was also no statistically significant difference according to the categories of thyroid function. In a previous study in our area evaluating older subjects (mean age at baseline 94 years), the mean TSH level was $3.10 \pm 6 \mathrm{mU} / \mathrm{l}$. The majority had normal thyroid function, while three (4\%) had abnormally high levels, and five (7\%) had abnormally low levels of TSH. Forty-four participants died during the follow-up period (67.1\%). There were no significant differences in serum TSH values in patients who died with respect to the survivors $(2.3 \pm 3.6$ vs $2.6 \pm 8.9, P=0.66)(13)$. These results contrast with those reported in another study with a larger sample (599 participants) followed up from age 85 years through age 89 years and with a much lower mortality rate $(37 \%)$ that showed an association between low thyroid function (high levels of TSH) and longevity (14). Our results are consistent with recent studies of younger subjects and longer follow-up periods that did not report any independent association of serum TSH and mortality, including a German study (younger than 65 years old with follow-up of 8.5 years) (10), the Longitudinal Aging Study Amsterdam (mean age of 75 with a follow-up of 10.7 years) (9) and the Osteoporotic Fractures in Men study (mean age 74 years, follow-up 8.3 years) (28). We chose a 3 -year follow-up period for this study because it represents about $50 \%$ of the years of life expectancy in 85 -year olds in our area (6.5 years) (18). Even when we evaluated only the oldest euthyroid subjects, plasma TSH was not associated with a lower risk of all-cause mortality, as it had been in The Aging in the Chianti Area study (6).

This study has several strengths, including its prospective design, comprehensive set of measurements and completeness of follow-up. An important strength of the OCTABAIX study is the use of a community-based sample of patients of the same age, and with no exclusion criteria. Therefore, this sample is representative of the socioeconomic characteristics of the older residents in our area, with the full range of comorbidities. All subjects were registered with a general practitioner and benefited from the full range of public health facilities. However, the same-age restriction might limit the value of the findings of our study when applied to an elderly population with a broader age range. The size of the sample population was the main limitation of this study, compared with previous studies (14), and consequently, there were few individuals with abnormal TSH values. One weakness of our study is that thyroid function was measured only once, despite evidence that abnormal TSH will spontaneously normalize in a substantial proportion (up to 25\%) of individuals (29). Another limitation is the fact that tri-iodothyronine levels were not available. Furthermore, we did not analyze the 
cause of death. In this respect, it should be noted that two recent meta-analyses on subclinical thyroid dysfunction suggest that there is an increased risk of adverse cardiovascular events in patients younger than 65 years, but not in older ones $(30,31)$.

In conclusion, a single measurement of serum $\mathrm{TSH}$ in a sample of individuals aged 85 years or older was not associated with functional or cognitive status, nor with increased 3-year mortality from all causes.

\section{Declaration of interest}

The authors declare that there is no conflict of interest that could be perceived as prejudicing the impartiality of the research reported.

\section{Funding}

This research did not receive any specific grant from any funding agency in the public, commercial or not-for-profit sector.

\section{Acknowledgements}

The authors would like to thank the members of the OCTABAIX study group: J Almeda (Unitat de Suport a la Recerca de Costa de Ponent, IDIAP J Gol), T Badia (ABS Martorell Urbano), O Cunillera (Unidad de suport a la recerca de Costa de Ponebt, IDIAp Jordi Gol), C Fernández (Cap Rambla), A Ferrer (CAP EI Pla), F Formiga (UFISS de Geriatría, Servicio de Medicina Interna, Hospital Universitari de Bellvitge), A Gil (ABS St Andreu de la Barca), C L Lopart (ABS Sant Andreu de la Barca), M J Megido (ABS Just Oliveras), G Padrós (Laboratori Clínic L'Hospitalet-Cornellà), M Sarró (CAP Florida Nord) and A Tobella (ABS Martorell Rural)

\section{References}

1 Vitale G, Salvioli S \& Franceschi C. Oxidative stress and the ageing endocrine system. Nature Reviews. Endocrinology 20139 228-240. (doi:10.1038/nrendo.2013.29)

2 Surks MI \& Hollowell JG. Age-specific distribution of serum thyrotropin and antithyroid antibodies in the US population: implications for the prevalence of subclinical hypothyroidism. Journal of Clinical Endocrinology and Metabolism 200792 4575-4582. (doi:10.1210/jc. 2007-1499)

3 Ceresini G, Ceda GP, Lauretani F, Maggio M, Usberti E, Marina M, Bandinelli S, Guralnik JM, Valenti G \& Ferrucci L. Thyroid status and 6-year mortality in elderly people living in a mildly iodine-deficient area: the aging in the Chianti area study. Journal of the American Geriatrics Society 201361 868-874. (doi:10.1111/jgs.12267)

4 Vitale G, Fatti LM, Prolo S, Girola A, Caraglia M, Marra M, Abbruzzese A, Gerli G \& Mari D. Screening for hypothyroidism in older hospitalized patients with anemia: a new insight into an old disease. Journal of the American Geriatrics Society 201058 1825-1827. (doi:10.1111/j.15325415.2010.03040.x)

5 Aghini-Lombardi F, Antonangeli L, Martino E, Vitti P, Maccherini D, Leoli F, Rago T, Grasso L, Valeriano R, Balestrieri A et al. The spectrum of thyroid disorders in an iodine-deficient community: the Pescopagano survey. Journal of Clinical Endocrinology and Metabolism 199984 561-566. (doi:10.1210/jc.84.2.561)

6 Ceresini G, Lauretani F, Maggio M, Ceda GP, Morganti S, Usberti E, Chezzi C, Valcavi R, Bandinelli S, Guralnik JM et al. Thyroid function abnormalities and cognitive impairment in elderly people: results of the Invecchiare in Chianti Study. Journal of the American Geriatrics Society 200957 89-93. (doi:10.1111/j.1532-5415.2008.02080.x)

7 Roberts LM, Pattison H, Roalfe A, Franklyn J, Wilson S, Hobbs FD \& Parle JV. Is subclinical thyroid dysfunction in the elderly associated with depression or cognitive dysfunction? Annals of Internal Medicine 2006145 573-581. (doi:10.7326/0003-4819-145-8-200610170-00006)

8 Simonsick EM, Newman AB, Ferrucci L, Satterfield S, Harris TB, Rodondi N, Bauer DC \& Health ABC Study. Subclinical hypothyroidism and functional mobility in older adults. Archives of Internal Medicine 2009169 2011-2017. (doi:10.1001/archinternmed.2009.392)

9 de Jongh RT, Lips P, van Schoor NM, Rijs KJ, Deeg DJ, Comijs HC, Kramer MH, Vandenbroucke JP \& Dekkers OM. Endogenous subclinical thyroid disorders, physical and cognitive function, depression, and mortality in older individuals. European Journal of Endocrinology 2011 165 545-554. (doi:10.1530/EJE-11-0430)

10 Ittermann T, Haring R, Sauer S, Wallaschofski H, Dörr M, Nauck M \& Völzke H. Decreased serum TSH levels are not associated with mortality in the adult northeast German population. European Journal of Endocrinology 2010162 579-585. (doi:10.1530/EJE-09-0566)

11 Parle JV, Maisonneuve P, Sheppard MC, Boyle P \& Franklyn JA. Prediction of all-cause and cardiovascular mortality in elderly people from one low serum thyrotropin result: a 10-year cohort study. Lancet 2001358 861-865. (doi:10.1016/S0140-6736(01)06067-6)

12 McQuade C, Skugor M, Brennan DM, Hoar B, Stevenson C \& Hoogwerf BJ. Hypothyroidism and moderate subclinical hypothyroidism are associated with increased all-cause mortality independent of coronary heart disease risk factors: a PreCIS database study. Thyroid 201121 1-7. (doi:10.1089/thy.2010.0298)

13 Formiga F \& Ferrer A. Thyrotropin serum values and 3-year mortality in nonagenarians. Journals of Gerontology. Series A, Biological Sciences and Medical Sciences 201065 1250-1251. (doi:10.1093/gerona/glq076)

14 Gussekloo J, van Exel E, de Craen AJ, Meinders AE, Frölich M \& Westendorp RG. Thyroid status, disability and cognitive function, and survival in old age. Journal of the American Medical Association 2004292 2591-2599. (doi:10.1001/jama.292.21.2591)

15 Atzmon G, Barzilai N, Hollowell JG, Surks MI \& Gabriely I. Extreme longevity is associated with increased serum thyrotropin. Journal of Clinical Endocrinology and Metabolism 200994 1251-1254. (doi:10.1210/ jc.2008-2325)

16 Rozing MP, Westendorp RG, de Craen AJ, Frölich M, Heijmans BT, Beekman M, Wijsman C, Mooijaart SP, Blauw GJ, Slagboom PE et al. Low serum free triiodothyronine levels mark familial longevity: the Leiden Longevity Study. Journals of Gerontology. Series A, Biological Sciences and Medical Sciences 201065 365-368. (doi:10.1093/gerona/ glp200)

17 Ferrer A, Badia T, Formiga F, Gild A, Padróse G, Sarróf M, Almedag J \& Pujolb R. Ensayo aleatorizado de prevención de caídas y malnutrición en personas de 85 años en la comunidad. Estudio OCTABAIX. Revista Española de Geriatría y Gerontología 201045 79-85. (doi:10.1016/j.regg. 2009.10.013)

18 Formiga F, Ferrer A, Chivite D, Montero A, Sanz H \& Pujol R. Utility of geriatric assessment to predict mortality in the oldest old. The Octabaix study: three-year follow-up. Rejuvenation Research 201316 279-284. (doi:10.1089/rej.2013.1422)

19 Mahoney FI \& Barthel DW. Functional evaluation: the Barthel index. A simple index of independence useful in scoring improvement in the rehabilitation of the chronically ill. Maryland State Medical Journal 1965 14 61-65.

20 Lawton MP \& Brody EM. Assessment of older people: self-maintaining and instrumental activities of daily living. Gerontologist 19699 179-186. (doi:10.1093/geront/9.3_Part_1.179)

21 Lobo A, Saz P, Marcos G, Día JL, De la Cámara C, Ventura T, Morales Asín F, Fernando Pascual L, Montañés JA \& Aznar S. Revalidación y normalización del Mini-Examen Cognoscitivo (primera versión en 
castellano del Mini-mental Status Examination) en la población general geriátrica. Medicina Clínica 1999112 767-774.

22 Guigoz Y, Vellas B \& Garry PJ. Assessing the nutritional status of the elderly: the Mini Nutritional Assessment as part of the geriatric evaluation. Nutrition Reviews $1996 \mathbf{5 4}$ (Suppl) 59-65.

23 Tinetti ME. Performance-oriented assessment of mobility problems in elderly patients. Journal of the American Geriatrics Society 198634 119-126.

24 Herdman M, Badia X \& Berra S. El EuroQol-5D: una alternativa sencilla para medir calidad de vida relacionada con salud en atención primaria. Atencion Primaria 200128 425-430. (doi:10.1016/S0212-6567(01)< ?A3B2 show $\$ 160$ ? > 70406-4)

25 Charlson ME, Pompei P, Ales KL \& MacKenzie CR. A new method of classifying prognostic comorbidity in longitudinal studies: development and validation. Journal of Chronic Diseases 198740 373-383. (doi:10.1016/0021-9681(87)90171-8)

26 von Heideken Wågert P, Gustafson Y, Kallin K, Jensen J \& LundinOlsson L. Falls in very old people: the population-based Umeå $85+$ study in Sweden. Archives of Gerontology and Geriatrics 200949 390-396. (doi:10.1016/j.archger.2008.12.005)

27 Park YJ, Lee EJ, Lee YJ, Choi SH, Park JH, Lee SB, Lim S, Lee WW, Jang HC, Cho BY et al. Subclinical hypothyroidism (SCH) is not associated with metabolic derangement, cognitive impairment, depression or poor quality of life (QoL) in elderly subjects. Archives of Gerontology and Geriatrics 201050 e68-e73. (doi:10.1016/j.archger. 2009.05.015)

28 Waring AC, Harrison S, Samuels MH, Ensrud KE, LeBLanc ES, Hoffman AR, Orwoll E, Fink HA, Barrett-Connor E, Bauer DC et al. Thyroid function and mortality in older men: a prospective study. Journal of Clinical Endocrinology and Metabolism 201297 862-870. (doi:10.1210/jc.2011-2684)

29 Díez JJ \& Iglesias P. Spontaneous subclinical hypothyroidism in patients older than 55 years: an analysis of natural course and risk factors for the development of overt thyroid failure. Journal of Clinical Endocrinology and Metabolism 200489 4890-4897. (doi:10.1210/jc. 2003-032061)

30 Ochs N, Auer R, Bauer DC, Nanchen D, Gussekloo J, Cornuz J \& Rodondi N. Meta-analysis: subclinical thyroid dysfunction and the risk for coronary heart disease and mortality. Annals of Internal Medicine 2008148 832-845. (doi:10.7326/0003-4819-148-11200806030-00225)

31 Razvi S, Weaver JU, Vanderpump MP \& Pearce SH. The incidence of ischemic heart disease and mortality in people with subclinical hypothyroidism: reanalysis of the Whickham Survey cohort. Journal of Clinical Endocrinology and Metabolism 201095 1734-1740. (doi:10.1210/ jc.2009-1749)

Received 2 September 2013

Revised version received 16 October 2013

Accepted 21 October 2013 